Check for updates

Cite this: RSC Adv., 2018, 8, 36150

\title{
New photoluminescent iodoargentates with bisimidazole derivatives as countercations $\uparrow$
}

\author{
Rong-Yan Wang, ${ }^{a}$ Xiao Zhang, (D) *b Jie-Hui Yu (D) *a and Ji-Qing Xu ${ }^{a}$
}

In this article, three bisimidazole derivatives (1,4-bis(2-ethylimidazol-1-yl)butane, L1; 4,4'-di(1H-imidazol-1yl)-1,1'-biphenyl, L2'; and 1,3-bis(2-ethylimidazol-1-yl)propane, L3) were employed to solvothermally react with $\mathrm{Agl}$ in an acidic environment, creating three new 1-D chained iodoargentates [H(L1)][Ag $\left.5 I_{6}\right]$. DMF (DMF $=\mathrm{N}, \mathrm{N}^{\prime}$-dimethylformamide) 1, [L2] $\left[\mathrm{Ag}_{3} \mathrm{I}_{5}\right]\left(\mathrm{L} 2^{2+}=4,4^{\prime}\right.$-di(1H-imidazol-1-ium)-1,1'-biphenyl) 2, and [ $\left.\mathrm{H}_{2}(\mathrm{~L} 3)\right]$ $\left[\mathrm{Ag}_{2} \mathrm{I}_{4}\right]$ 3. $\mathrm{L}^{2+}$ in 2 originated from the in situ $\mathrm{N}$-alkylation of $\mathrm{L}^{\prime}{ }^{\prime}$ with the $\mathrm{CH}_{3} \mathrm{OH}$ solvent. $\mathrm{X}$-ray singlecrystal diffraction analysis reveals that (i) in $1, \mathrm{Ag}^{+}$and $\mathrm{I}^{-}$aggregate to form a $1-\mathrm{D}$ tube-like iodoargentate, which exhibits the same topology as the carbon tube; (ii) the chain structure of the iodoargentate in 2 is based on a kind of trinuclear $\mathrm{Ag}-1$ cluster, which can be viewed as a segment of the classical cubic $\mathrm{M}_{4} \mathrm{l}_{4}$ cluster; (iii) the chain structure of the iodoargentate in 3 is simple, which can be described as a linear arrangement of the $\mathrm{Agl}_{4}$ tetrahedra by sharing edges. The photoluminescence analysis reveals that at $77 \mathrm{~K}$, (i) 1 and 2 emit strong yellow light with ms-grade photoluminescence lifetimes (5.460 ms for 1, $6.931 \mathrm{~ms}$ for 2); (ii) 3 possesses photochromic luminescence properties. Upon excitation at $254 \mathrm{~nm}$, it emits blue-green light, whereas upon excitation at $365 \mathrm{~nm}$, it emits yellow light.

Received 6th July 2018

Accepted 12th October 2018

DOI: $10.1039 / \mathrm{c} 8 \mathrm{ra05760e}$

rsc.li/rsc-advances material. For instance, the superoxide ion $\cdot \mathrm{O}_{2}{ }^{-}$has been confirmed to be the dominant reactive species for the degradation of the organic dyes. Just due to a hybrid process of the inorganic and organic moieties, the electronic structure and the band gap for the material are changed, which makes the photogenerated electrons more easily transfer. Then the electrons are further to be trapped by $\mathrm{O}_{2}$ to form $\cdot \mathrm{O}_{2}{ }^{-8}$ The pre-synthesized organic base derivatives (through the $\mathrm{N}$-alkylation of organic bases with organic halides), ${ }^{6}$ in situ generated complexes, ${ }^{8}$ and the in situ protonated organic bases ${ }^{1}$ can all be employed to serve as the countercations. Recently, the in situ $\mathrm{N}$-alkylation of organic bases with alcohol molecules has also been employed to create the new countercations. ${ }^{9}$ So far, the in situ N-alkylation of pyridine derivatives with alcohol molecules have been extensively employed in the construction of new organic-inorganic hybrid materials, but the in situ $\mathrm{N}$-alkylation of imidazole derivatives with alcohol molecules is seldom considered. ${ }^{10}$ In addition, based on our investigations, the in situ protonation of imidazole derivatives has seldom employed in the construction of the iodoargentate.

At recent, the tunable photoluminescence materials have gained the considerable interest owing to their potential technological applications in light emitting diodes, bioimaging and memories. ${ }^{11}$ Although the degradation on organic dyes as well as the thermo(photo)chromism for the hybrid haloargentates have been well developed, ${ }^{3,4,7,8}$ the investigations on the photoluminescence behaviors for this type of material are still limited. For the reported hybrid haloargentates, only the roomtemperature photoluminescence behaviors were characterized, 
whereas the photoluminescence behaviors with the change of temperature and excitation wavelength (namely the so-called luminescence thermo(photo)chromic properties) as well as the photoluminescence lifetime are rarely investigated. ${ }^{2,6}$ Many $\mathrm{Cu}^{\mathrm{I}}-\mathrm{X}$ cluster-based compounds have been proved to be the excellent photoluminescence thermochromic materials. ${ }^{12}$ This is mainly due to the following two factors: (i) considerable flexibility for $\mathrm{Cu}^{\mathrm{I}}-\mathrm{X}$ cluster. The $\mathrm{Cu}^{\mathrm{I}}-\mathrm{I}$ cluster easily distorts upon external stimulus; (ii) considerable sensibility of photoluminescence behavior for $\mathrm{Cu}^{\mathrm{I}}-\mathrm{I}$ cluster. A minor distinction in structure can produce a big variation of the photoluminescence behavior. ${ }^{13} \mathrm{As}$ an element of the same group as $\mathrm{Cu}$, do the Ag-I cluster-based hybrids also possess the photoluminescence thermochromic properties? The photoluminescence photochromic property is generally associated with the existence of multiple emissions in the molecule. ${ }^{13}$ So far, only extremely limited hybrids have been found to possess this property, such as $[\mathrm{bmim}]_{2}\left[\mathrm{SbCl}_{5}\right]\left(\mathrm{bmim}^{+}=1\right.$-butyl-3-methylimidazolium $),{ }^{14}$ [spy $]\left[\mathrm{CdCl}_{2}\left(\mathrm{H}_{2} \mathrm{O}\right)_{2}\right] \quad$ (spy $=N$-succinopyridine) ${ }^{15}$ and $[\text { dmdabco }]_{2}\left[\mathrm{Cu}_{4} \mathrm{Br}_{5}(\mathrm{CN})_{3}\right]$ (dmdabco ${ }^{2+}=N, N^{\prime}$-dimethyl-1,4-diazabicyclo[2,2,2]octanium). ${ }^{13}$ Do the Ag-I cluster-based hybrids have the photoluminescence photochromic properties? What about the photoluminescence lifetimes? Based on these questions, in this article we constructed three new 1-D chained iodoargentates by employing three bisimidazole derivatives (1,4-bis(2-ethylimidazol-1-yl)butane, L1; 4,4'-di(1H-imidazol-1yl)-1,1'-biphenyl, L2'; 1,3-bis(2-ethylimidazol-1-yl)propane, L3) as the countercations: $[\mathrm{H}(\mathrm{L} 1)]\left[\mathrm{Ag}_{5} \mathrm{I}_{6}\right] \cdot \mathrm{DMF}$ (DMF $=N, N^{\prime}$-dimethylformamide) 1, [L2] $\left[\mathrm{Ag}_{3} \mathrm{I}_{5}\right]\left(\mathrm{L}^{2+}=4,4^{\prime}\right.$-di(1H-imidazol-1ium)-1,1'-biphenyl) 2, and $\left[\mathrm{H}_{2}(\mathrm{~L} 3)\right]\left[\mathrm{Ag}_{2} \mathrm{I}_{4}\right]$ 3. Of those, $\mathrm{L2}^{2+}$ originated from the in situ $\mathrm{N}$-alkylation of 4,4'-di(1H-imidazol-1yl)-1,1'-biphenyl ( $\mathrm{L2}^{\prime}$ ) with $\mathrm{CH}_{3} \mathrm{OH}$. The photoluminescence behaviors of these three hybrids at $298 \mathrm{~K}, 177 \mathrm{~K}$, and $77 \mathrm{~K}$ were measured. Their photoluminescence behaviors under the different excitation wavelengths were investigated. Their photoluminescence lifetimes were also measured (Scheme 1).

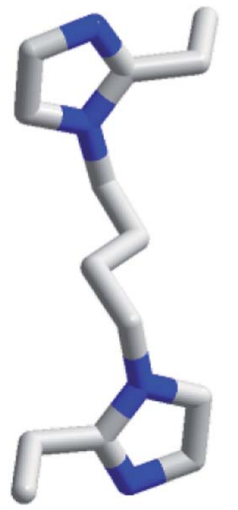

L1
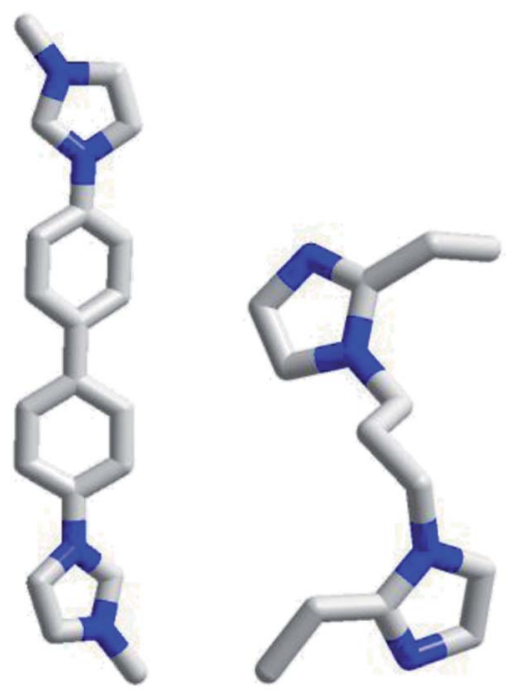

L3
Scheme 1 Molecular structures of organic bases in 1-3

\section{Experimental}

\section{Materials and physical measurement}

All chemicals are of reagent grade quality, obtained from commercial sources without further purification. Elemental analysis (C, H and N) was performed on a Perkin-Elmer 2400LS II elemental analyzer. Infrared (IR) spectrum was recorded on a Perkin Elmer Spectrum 1 spectrophotometer in 4000$400 \mathrm{~cm}^{-1}$ region using a powdered sample on a $\mathrm{KBr}$ plate. Powder X-ray diffraction (XRD) data were collected on a Rigaku/ max-2550 diffractometer with $\mathrm{Cu}-\mathrm{K}_{\alpha}$ radiation $(\lambda=1.5418 \AA$ ). Thermogravimetric (TG) behavior was investigated on a PerkinElmer TGA-7 instrument with a heating rate of $10^{\circ} \mathrm{C} \mathrm{min}{ }^{-1}$ in air. Ultraviolet-visible (UV-Vis) spectrum was obtained on a Rigaku-UV-3100 spectrophotometer. Fluorescence spectra were recorded on a LS 55 florescence/phosphorescence spectrophotometer at room temperature. Fluorescence lifetime was measured on an Edinburgh Instrument FLS920 steady-state transient fluorescence spectrometer.

\section{Synthesis of 1-3}

$[\mathbf{H}(\mathbf{L 1})]\left[\mathbf{A g}_{5} \mathbf{I}_{6}\right] \cdot$ DMF 1 . The yellow block crystals of 1 were obtained from a simple solvothermal self-assembly of AgI (12 $\mathrm{mg}, 0.05 \mathrm{mmol}$ ) and $\mathrm{L} 1$ (13 $\mathrm{mg}, 0.05 \mathrm{mmol})$ in a mixed solvent of $2 \mathrm{~mL} \mathrm{C}_{2} \mathrm{H}_{5} \mathrm{OH}$ and $3 \mathrm{~mL} \mathrm{DMF}(\mathrm{pH}=5)$ at $100{ }^{\circ} \mathrm{C}$ for 3 days. Yield: $c a$. $20 \%$ based on $\mathrm{Ag}(\mathrm{I})$. Anal. Calcd $\mathrm{C}_{17} \mathrm{H}_{30} \mathrm{~N}_{5} \mathrm{OAg}_{5} \mathrm{I}_{6}$ 1: C 12.59, H 1.87, N 4.32. Found: C 12.29, H 2.05, N 4.53\%. IR $\left(\mathrm{cm}^{-1}\right): 1672 \mathrm{~s}, 1442 \mathrm{w}, 1387 \mathrm{~m}, 1255 \mathrm{~m}, 1092 \mathrm{~s}, 1058 \mathrm{w}, 1046 \mathrm{w}$, $920 \mathrm{w}, 794 \mathrm{~m}, 745 \mathrm{~s}, 723 \mathrm{~s}, 662 \mathrm{~m}, 625 \mathrm{w}$.

$[\mathbf{L} 2]\left[\mathbf{A g}_{3} \mathbf{I}_{5}\right]$ 2. The yellow block crystals of 2 were obtained from a simple solvothermal self-assembly of AgI (23 mg, 0.1 $\mathrm{mmol}$ ), L2 (29 mg, $0.1 \mathrm{mmol})$ and $\mathrm{HI}(1 \mathrm{~mL} \mathrm{45 \% )}$ in a mixed solvent of $4 \mathrm{~mL} \mathrm{CH} \mathrm{CH}_{3} \mathrm{OH} 1 \mathrm{~mL} \mathrm{CH}_{3} \mathrm{CN}(\mathrm{pH}=2)$ at $120{ }^{\circ} \mathrm{C}$ for 3 days. Yield: $c a$. $35 \%$ based on $\mathrm{Ag}(\mathrm{I})$. Anal. Calcd $\mathrm{C}_{20} \mathrm{H}_{20} \mathrm{~N}_{4} \mathrm{Ag}_{3} \mathrm{I}_{5}$ 2: C 18.85, H 1.58, N 4.40. Found: C 18.21, H 1.42, N 4.72\%. IR $\left(\mathrm{cm}^{-1}\right): 3092 \mathrm{w}, 3016 \mathrm{~s}, 1628 \mathrm{w}, 1589 \mathrm{w}, 1494 \mathrm{~m}, 1460 \mathrm{w}, 1419 \mathrm{w}$, 1347 w, 1289 w, 1260 w, 1227 s, 1074 m, 952 w, 851 m, 826 s, 763 m, $724 \mathrm{w}, 703 \mathrm{w}, 614 \mathrm{~m}, 517 \mathrm{~m}$.

$\left[\mathbf{H}_{2}(\mathbf{L 3})\right]\left[\mathbf{A g}_{2} \mathbf{I}_{4}\right]$ 3. The yellow block crystals of $\mathbf{3}$ were obtained from a simple solvothermal self-assembly of AgI $(23 \mathrm{mg}, 0.1$ $\mathrm{mmol})$, L3 (18 mg, $0.1 \mathrm{mmol})$ and $\mathrm{HI}(0.25 \mathrm{~mL} 45 \%)$ in $7 \mathrm{~mL}$ $\mathrm{C}_{2} \mathrm{H}_{5} \mathrm{OH}(\mathrm{pH}=2)$ at $120{ }^{\circ} \mathrm{C}$ for 3 days. Yield: $c a$. $25 \%$ based on $\mathrm{Ag}(\mathrm{I})$. Anal. Calcd $\mathrm{C}_{13} \mathrm{H}_{22} \mathrm{~N}_{4} \mathrm{Ag}_{2} \mathrm{I}_{4}$ 3: C 16.30, H 2.30, N 5.85. Found: C 16.20, H 2.47, N 5.96\%. IR (cm $\left.{ }^{-1}\right): 1593$ s, $1450 \mathrm{~m}$, 1419 m, 1393 m, 1299 s, 1109 s, 1064 w, 1030 w, 1004 w, 980 w, $923 \mathrm{~m}, 870 \mathrm{w}, 854 \mathrm{w}, 806 \mathrm{w}, 794 \mathrm{w}, 770 \mathrm{~m}, 742 \mathrm{~s}$.

\section{X-ray crystallography}

The data were collected with Mo- $\mathrm{K}_{\alpha}$ radiation $(\lambda=0.71073 \AA)$ on a Rigaku R-AXIS RAPID IP diffractometer for $\mathbf{1}$ and 2, and on a Siemens SMART CCD diffractometer for 3. With SHELXTL program, the structures of $\mathbf{1}$ and $\mathbf{2}$ were solved using direct methods, whereas the structure of $\mathbf{3}$ was solved using heavy-atom methods. ${ }^{16}$ The non-hydrogen atoms were assigned anisotropic displacement parameters in the refinement. The hydrogen atoms were treated using a riding model. The structures were then 
Table 1 Crystal data of 1-3

\begin{tabular}{|c|c|c|c|}
\hline & 1 & 2 & 3 \\
\hline Formula & $\mathrm{C}_{17} \mathrm{H}_{30} \mathrm{~N}_{5} \mathrm{OAg}_{5} \mathrm{I}_{6}$ & $\mathrm{C}_{20} \mathrm{H}_{20} \mathrm{~N}_{4} \mathrm{Ag}_{3} \mathrm{I}_{5}$ & $\mathrm{C}_{13} \mathrm{H}_{22} \mathrm{~N}_{4} \mathrm{Ag}_{2} \mathrm{I}_{4}$ \\
\hline$M$ & 1621.21 & 1274.51 & 957.69 \\
\hline$T(\mathrm{~K})$ & $293(2)$ & $293(2)$ & $299(2)$ \\
\hline Crystal system & Monoclinic & Monoclinic & Triclinic \\
\hline Space group & $\mathrm{Cm}$ & $P 2_{1} / c$ & $P \overline{1}$ \\
\hline$a(\AA)$ & $21.078(4)$ & $18.655(4)$ & $7.2734(2)$ \\
\hline$b(\AA)$ & $21.543(4)$ & $13.100(3)$ & $9.8577(2)$ \\
\hline$c(\AA)$ & $7.9092(16)$ & $12.832(3)$ & $16.4819(4)$ \\
\hline$\alpha\left(^{\circ}\right)$ & 90 & 90 & $81.4680(10)$ \\
\hline$\beta\left(^{\circ}\right)$ & $107.59(3)$ & $110.08(3)$ & $87.2330(10)$ \\
\hline$\gamma\left(\left(^{\circ}\right)\right.$ & 90 & 90 & $85.0890(10)$ \\
\hline$V\left(\AA^{3}\right)$ & $3423.5(11)$ & 2945.3(10) & $1163.61(5)$ \\
\hline$Z$ & 4 & 4 & 2 \\
\hline$D_{\mathrm{c}}\left(\mathrm{g} \mathrm{cm}^{-3}\right)$ & 3.145 & 2.874 & 2.733 \\
\hline$\mu\left(\mathrm{mm}^{-1}\right)$ & 8.240 & 7.232 & 6.992 \\
\hline Reflections collected & 13589 & 25104 & 25513 \\
\hline Unique reflections & 6062 & 6547 & 5759 \\
\hline$R_{\text {int }}$ & 0.0279 & 0.0413 & 0.0239 \\
\hline Gof & 1.043 & 1.034 & 1.038 \\
\hline$R_{1}, I>2 \sigma(I)$ & 0.0298 & 0.0392 & 0.0248 \\
\hline$w R_{2}$, all data & 0.0644 & 0.0869 & 0.0530 \\
\hline
\end{tabular}

refined on $F^{2}$ using SHELXL-2018. ${ }^{16}$ The CCDC numbers are 1818391 for $\mathbf{1}, 1818388$ for 2 and 1818390 for 3 , respectively (Table 1).

\section{Results and discussion}

\section{Synthetic analysis}

All of the reactions were carried out under the solvothermal conditions. In general, such a reaction of AgI, organic bisimidazole molecule and $\mathrm{HI}$ will be investigated, as exemplified by the reactions of preparing 2 and 3 . Here HI possesses the following several roles: (i) providing a strong acid source. This is helpful to the thorough protonation of the organic bisimidazole molecule. On the other hand, the in situ $\mathrm{N}$-alkylation of organic bisimidazole molecules with alcohol molecules also needs a strongly acidic environment; (ii) providing the extra $\mathrm{I}^{-}$source; (iii) improving the solubility of the reactive precursors in the solvent. Obviously, the reaction of preparing 1 shows an exceptional situation. In the presence of HI, no any crystalline solid was obtained. But without HI, the title compound $\mathbf{1}$ was luckily obtained. Without HI, the acidic degree of reactive system is not high, so the bisimidazole molecule is just to be monoprotonated. The formation of the iodoargentate in $\mathbf{1}$ $\left(\left[\mathrm{Ag}_{5} \mathrm{I}_{6}\right]^{-}\right)$should be associated with the +1 oxidation state of the bisimidazole molecule. The reactions were generally performed in an alcohol solvent. The aim is to hope that the in situ $\mathrm{N}$ alkylation of organic bisimidazole molecule with alcohol molecule could occur, creating a new countercation. Regretfully, only in the reaction of synthesizing 2 , the in situ $\mathrm{N}$ alkylation occurred. In the reactions of synthesizing $\mathbf{1}$ and $\mathbf{3}$, the in situ alkylation was not observed. This might be due to the existence of the substituted $-\mathrm{C}_{2} \mathrm{H}_{5}$ group on the imidazole moiety of L1 and L3. As exemplified by the reactions of preparing 1 and 2, another kind of strong polar solvent was sometimes used to aid the alcohol molecule to dissolve the reactive precursors (DMF for $\mathbf{1}, \mathrm{CH}_{3} \mathrm{CN}$ for 2). Interestingly, the solvent DMF was introduced in the final backbone of $\mathbf{1}$. We are sure that DMF also plays a crucial role in the formation of the inorganic anionic framework for 1, because when DMA $(N, N-$ dimethylacetamide) instead of DMF was used, a different iodoargentate was obtained. Regretfully, the crystal data of this compound do not pass the cif-checking examination. In addition, 1,4-di( $1 H$-imidazol-1-yl)benzene (L4) was also employed to react with AgI, creating the compound $\left[\mathrm{H}_{2}(\mathrm{~L} 4)\right]\left[\mathrm{Ag}_{2} \mathrm{I}_{4}\right] \mathbf{4}$. Regretfully, due to the severe disorder of the imidazole rings, the crystal data of $\mathbf{4}$ do not pass the cif-checking examination, either. A bistriazole molecule (1,3-di(1H-1,2,4-triazol-1-yl) propane, $\mathrm{L}^{\prime}$ ) was also employed to react with $\mathrm{AgI}$ in $\mathrm{C}_{2} \mathrm{H}_{5} \mathrm{OH}$, producing the compound [L5][ $\left.\mathrm{Ag}_{2} \mathrm{I}_{4}\right]\left(\mathrm{L}^{2+}=2\right.$-ethyl-1-(3-(4-

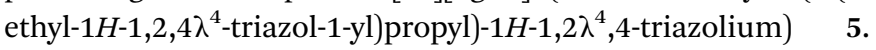
Note that the in situ $\mathrm{N}$-alylation of bistriazole with $\mathrm{C}_{2} \mathrm{H}_{5} \mathrm{OH}$ was observed for the first time. Regretfully, the pure $\mathbf{5}$ was not obtained so far.

\section{Structural description}

$[\mathbf{H}(\mathbf{L 1})]\left[\mathbf{A g}_{5} \mathbf{I}_{6}\right] \cdot$ DMF 1. X-ray single-crystal diffraction analysis reveals that $\mathbf{1}$ is a 1-D tubed iodoargentate with $\mathrm{H}(\mathrm{L} 1)^{+}$as the countercation. The solvent molecule DMF also appears in the final framework of $\mathbf{1}$. It crystallizes in a non-centric space group $\mathrm{Cm}$, and the asymmetric unit (see Fig. 1a) is found to be composed of six $\mathrm{Ag}^{+}$ions (occupancy ration: 1 for Ag1, Ag2, Ag3, Ag4; 0.5 for Ag5, Ag6; 5 for all), eight $\mathrm{I}^{-}$ions (occupancy ratio: 1 for I4, I5, I6, I8; 0.5 for I1, I2, I4, I7; 6 for all), one L1 molecule, and two DMF molecules (occupancy ratio: 0.5 for each atom). L1 should be monoprotonated in order to balance the anionic charge $\left(\left[\mathrm{Ag}_{5} \mathrm{I}_{6}\right]^{-}\right)$. Fig. 1b illustrates the structure of the inorganic anion $\left[\mathrm{Ag}_{5} \mathrm{I}_{6}\right]^{-}$. All of the $\mathrm{Ag}^{+}$ions together with six $\mathrm{I}^{-}$ions (I3-I8) construct a 1-D endless tube, running down the $c$-axial direction. The other two $\mathrm{I}^{-}$ions (I1, I2) are distributed on the centric axis of the tube. Actually, all of the $\mathrm{Ag}^{+}$ions form the covalent bonds to I1 or I2. For clarity and better understanding its structure, these bonds are omitted. All of the $\mathrm{Ag}^{+}$ions in $\mathbf{1}$ are tetrahedrally coordinated by four $\mathrm{I}^{-}$ions. The $\mathrm{Ag}$-I1/I2 bonds (2.9320(19)-3.0042(11) $\AA$ ) are obviously longer than the others (2.8151(11)-2.8766(13) ̊). Eight $\mathrm{I}^{-}$ions adopt two types of geometric configurations. The $\mathrm{I}^{-}$ions on the tube all adopt a trigonal pyrimidal configuration, whereas I1 and I2 adopt a pentagonal pyrimidal configuration (see Fig. S1†). According. to the topological method, $\mathrm{Ag}^{+}$and $\mathrm{I}^{-}$on the tube are all viewed as a 3-connected node, so this tube has the same topology as the carbon tube. Fig. $1 \mathrm{c}$ is the projection plot of $\mathbf{1}$ in the (001) direction. Via the $\mathrm{N}_{\text {imidazole }}-\mathrm{H} \cdots \mathrm{N} 2 \mathrm{a}_{\text {imidazole }}$ interactions ( $\mathrm{N} 1 \cdots$ $\mathrm{N} 2 \mathrm{a}=2.707(9) \AA)$, the adjacent $\mathrm{H}(\mathrm{L} 1)^{+}$molecules self-assemble into a 1-D castellated supramolecular chain, extending along the $a$-axial direction. Along the $c$-axial direction, the neighboring supramolecular chains array in a parallel way, while along the $b$-axial direction, the adjacent supramolecular chains array in the form of mirror symmetry. Thus, two types of spaces appear. The anionic tube occupies the larger space, whereas the 


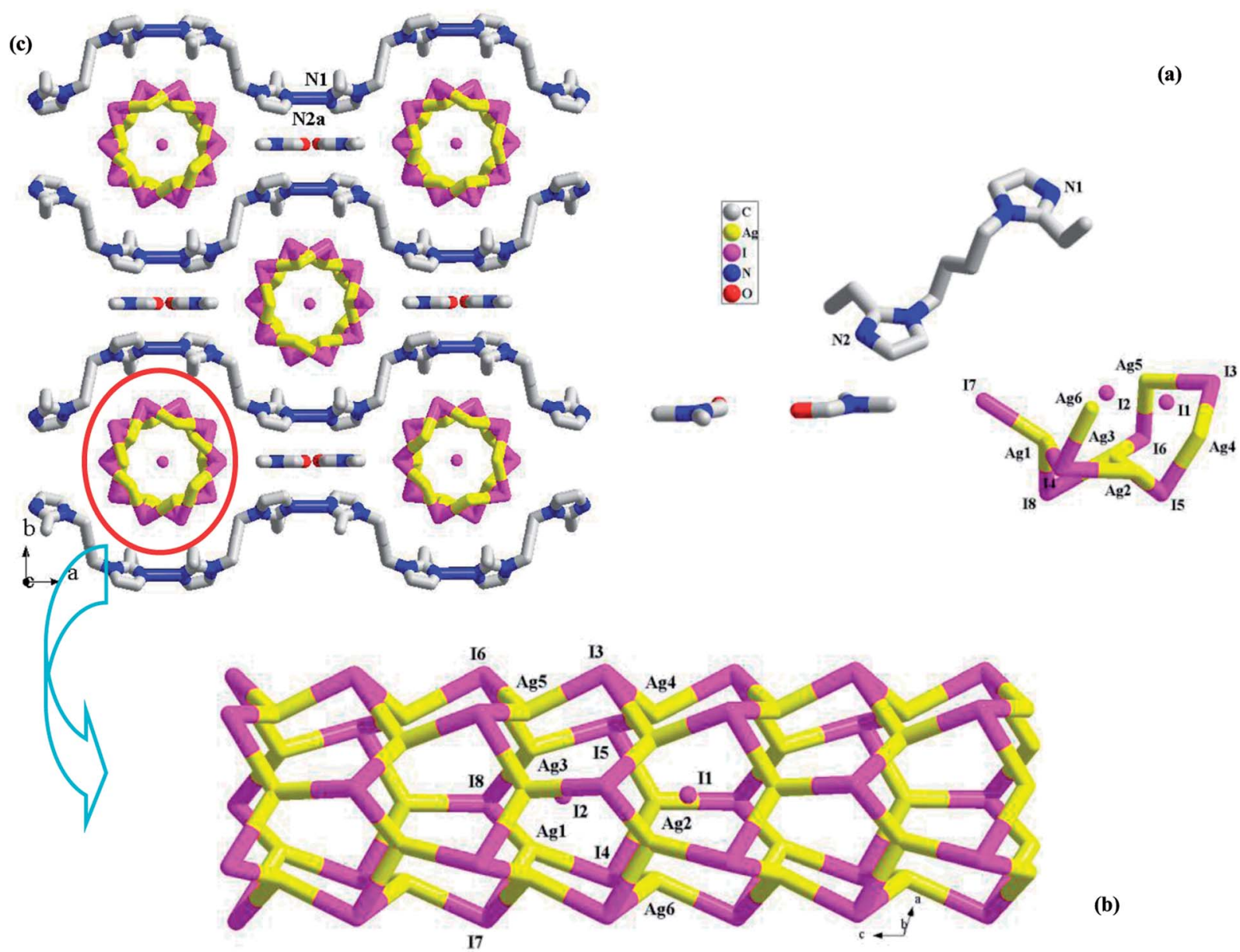

Fig. 1 Asymmetric unit (a), 1-D chain (b), and projection plot in (001) direction (c) in 1 (a: $x+1 / 2,-y+1 / 2, z)$.

DMF molecules occupy the smaller space. The shortest Ag $\cdots \mathrm{Ag}$ contact distance in 1 is Ag1 $\cdots \mathrm{Ag} 3=3.1832(14) \AA$.

$[\mathbf{L} 2]\left[\mathbf{A g}_{3} \mathbf{I}_{5}\right] \mathbf{2 .} 2$ is a L2 ${ }^{2+}$-templated 1-D chained iodoargentate. Obviously, the in situ $\mathrm{N}$-alkylation of $\mathrm{L}^{\prime}$ with $\mathrm{CH}_{3} \mathrm{OH}$ really occurred, producing $\mathrm{L}_{2}{ }^{2+}$. Compound 2 crystallizes in the space group $P 2_{1} / c$, and the asymmetric unit is found to be composed of three $\mathrm{Ag}^{+}$ions (Ag1, Ag2, Ag3), five $\mathrm{I}^{-}$ions (I1, I2, I3, I4, I5), and one $\mathrm{L}^{2+}$ molecule (see Fig. 2a). Fig. 2b illustrates the chain structure of the inorganic anion $\left[\mathrm{Ag}_{3} \mathrm{I}_{5}\right]^{2-}$. The chain is based on a kind of trinuclear Ag-I cluster. This trinuclear cluster can be described as a moiety of the classical cubic $\mathrm{M}_{4} \mathrm{I}_{4}$ cluster $\left(\mathrm{M}^{+}=\right.$ $\left.\mathrm{Cu}^{+}, \mathrm{Ag}^{+}\right) .{ }^{17}$ The removal of one $\mathrm{M}^{+}$ion for cubic $\mathrm{M}_{4} \mathrm{I}_{4}$ cluster forms this trinuclear cluster. Then via the intercluster Ag-I

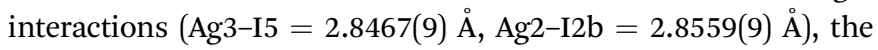
neighboring trinuclear clusters are linked together to form the title 1-D chain of 2, which extends along the $c$-axial direction. In 2, three $\mathrm{Ag}^{+}$ions are all in a tetrahedral site, and coordinated by four $\mathrm{I}^{-}$ion. The Ag-I bond length range is 2.7360(9)-2.9517(14) $\AA$. Five $\mathrm{I}^{-}$ions are involved in three types of coordination modes: a terminal mode for I4; a double bridged mode for I1; a triple bridged mode with a trigonal pyrimidal configuration for I2, I3 and I5. The shortest $\mathrm{Ag} \cdots \mathrm{Ag}$ contact distance in 2 is $\mathrm{Ag} 1 \cdots \mathrm{Ag} 2=$ 3.0325(11) A. Fig. 2c is the projection plot of 2 in the (001) direction. Via the $\pi \cdots \pi$ interactions between the $\mathrm{L}_{2}{ }^{2+}$ molecules, the adjacent $\mathrm{L}^{2+}$ molecules self-assemble into a supramolecular chain, running down the $c$-axial direction. Each four supramolecular chains enclose a square channel. The inorganic anion $\left[\mathrm{Ag}_{3} \mathrm{I}_{5}\right]^{2-}$ occupies the channel space. Between the $\mathrm{L}^{2+}$ molecule and the inorganic anion, there exist the $\mathrm{C}-\mathrm{H} \cdots \mathrm{I}$ hydrogenbonded interactions, stabilizing the crystal structure of 2. For clarity, these $\mathrm{C}-\mathrm{H} \cdots \mathrm{I}$ interactions are omitted.

$\left[\mathbf{H}_{2}(\mathbf{L} 3)\right]\left[\mathbf{A g}_{2} \mathbf{I}_{4}\right] \quad 3.3$ is a $\mathrm{H}_{2}(\mathbf{L} 3)^{2+}$-templated 1-D chained iodoargentate. It crystallizes in the space group $P \overline{1}$, and the asymmetric unit is found to be composed of two $\mathrm{Ag}^{+}$ions ( $\mathrm{Ag} 1$, Ag2), four $\mathrm{I}^{-}$ions (I1, I2, I3, I4), and one $\mathrm{H}_{2}(\mathrm{~L} 3)^{2+}$ molecule (see Fig. 3a). Fig. 3b illustrates a 2-D supramolecular layer network in 3, which is constructed up from the Ag-I chains by the $\mathrm{H}_{2}(\mathrm{~L} 3)^{2+}$ molecules. In the $\mathrm{Ag}-\mathrm{I}$ chain, two crystallographically independent $\mathrm{Ag}^{+}$ions $(\mathrm{Ag} 1, \mathrm{Ag} 2)$ are in a tetrahedral site, and surrounded by four $\mathrm{I}^{-}$ions. The Ag-I bond length range is $2.8300(4)-2.8926(4) \AA$. Four $\mathrm{I}^{-}$ions all adopt a $\mu_{2}$-bridging mode. The $\mathrm{I}^{-}$ions doublely bridge the tetrahedral $\mathrm{Ag}^{+}$ions to form this 1-D Ag-I chain of 3, which can also be described as a linear arrangement of the $\mathrm{AgI}_{4}$ tetrahedra by sharing the edges. The shortest $\mathrm{Ag} \cdots \mathrm{Ag}$ contact distance in the chain is $\mathrm{Ag} 1 \cdots \mathrm{Ag} 2=3.645 \AA$. I1 and $\mathrm{I} 3$ form the hydrogen bonds to the

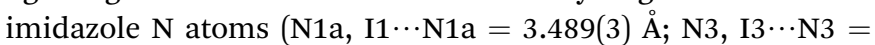
$3.500(3) \AA)$. Via these $\mathrm{N}-\mathrm{H} \cdots \mathrm{I}$ interactions, the $\mathrm{H}_{2}(\mathrm{~L} 3)^{2+}$ 
molecules link the $\left[\mathrm{Ag}_{2} \mathrm{I}_{4}\right]^{2-}$ chains into a 2-D supramolecular layer network. If $\mathrm{Ag}^{+}, \mathrm{I} 2$ and $\mathrm{I} 4$ are ignored, this 2-D supramolecular layer network can be simplified into a $6^{3}$ net. Fig. $3 \mathrm{c}$ is the projection plot of 3 in the (100) direction. Between the supramolecular layers, there exists the weak C-H $\cdots$ I interactions. For clarity, they are omitted.

\section{Structural discussion}

All of the title compounds are new, and have never been reported. In 1-3, the different organic bisimidazole molecules are employed, producing three different iodoargentates: the tubed iodoargentate in $\mathbf{1}$; the cluster-based chained iodoargentate in 2; the Ag-I single chain in 3 . The formation of the iodoargentate should be related to the organic bisimidazole molecule. Through the charge, size, form, and the various hydrogen-bonded interactions with the iodoargentate, the bisimidazole molecule directly controls the backbone structure of the iodoargentate. For example, (i) in 1, the L1 molecule is just to be monoprotonated, and has a +1 charge, so an iodoargentate with a -1 charge is formed; (ii) the cubic $\mathrm{M}_{4} \mathrm{I}_{4}$ cluster is a classical structure. The aim of the appearance for the terminal $\mathrm{I}^{-}$ion as well as the removal of an apical $\mathrm{Ag}^{+}$ion in 2 should be to balance the +2 charge of the counteraction $\left(\mathrm{L}^{2+}\right)$; (iii) in $\mathbf{1}$, due to the better flexibility of L1, they selfassemble into a 1-D castellated supramolecular chain, which leads to the appearance of the larger space. Such a space should be associated with the formation of the iodoargentate tube in $\mathbf{1}$; (iv) in the packing structures of $\mathbf{1 - 3}$, many $\mathrm{N}-\mathrm{H} \cdots \mathrm{I}$ and $\mathrm{C}-\mathrm{H} \cdots \mathrm{I}$ hydrogen-bonded interactions are found (see Table S1 $\dagger$ ). Their roles should not be ignored. The formation of the iodoargentate should also be related to the solvent molecule, as exemplified by $\mathbf{1}$. The Ag-I single chain in $\mathbf{3}$ has been frequently observed in the reported iodoargentates..$^{1 a, d, 2 e}$ However, only in the limited examples, ${ }^{2 b, 4 c, 7 h}$ the tubed iodoargentate in $\mathbf{1}$ and the cluster-based iodoargentate in $\mathbf{2}$ have ever been found. Even though the same iodoargentates are found in the different compounds, the $\mathrm{Ag}-\mathrm{I}$ and $\mathrm{Ag} \cdots \mathrm{Ag}$ interactions are generally different. This will directly influence some functional property of the material. Meanwhile, the different packing structures will be formed. For instance, the same Ag-I singe chains are found in 3 and 4 , but in 3, the 2-D supramolecular layer is found, whereas in $\mathbf{4}$, the pore yet appears $\left(c a .500 \AA^{3}\right)$.

\section{Characterization}

Fig. $\mathrm{S} 2 \uparrow$ presents the experimental and simulated powder XRD patterns of 1-3. The experimental powder XRD pattern for each compound is in accord with the simulated one generated on the basis of structural data, confirming that the as-synthesized product is pure phase. The TG behaviors of the title compounds in the temperature range of $30-800{ }^{\circ} \mathrm{C}$ were investigated. Based on their TG carves (Fig. S3 $\dagger$ ), we can know that (i)
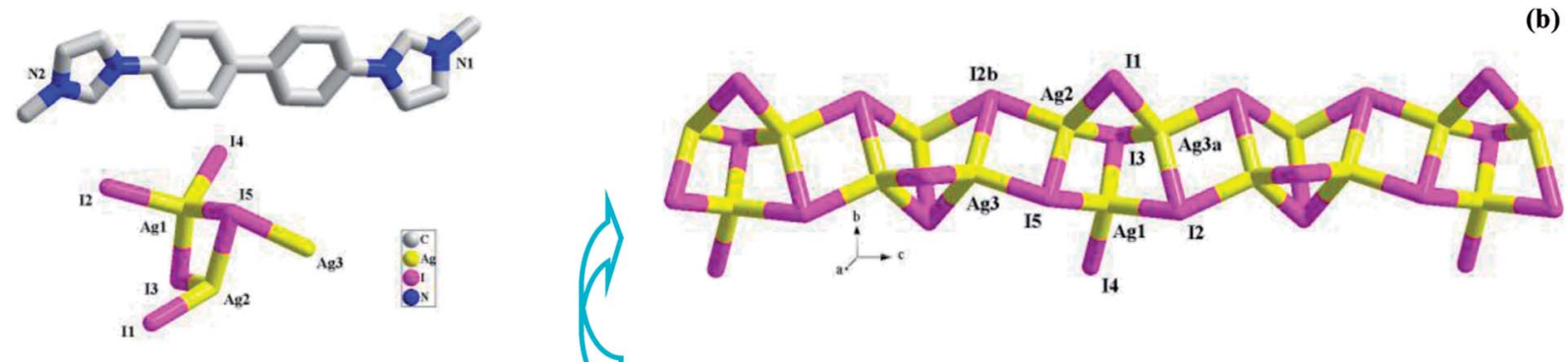

(a)

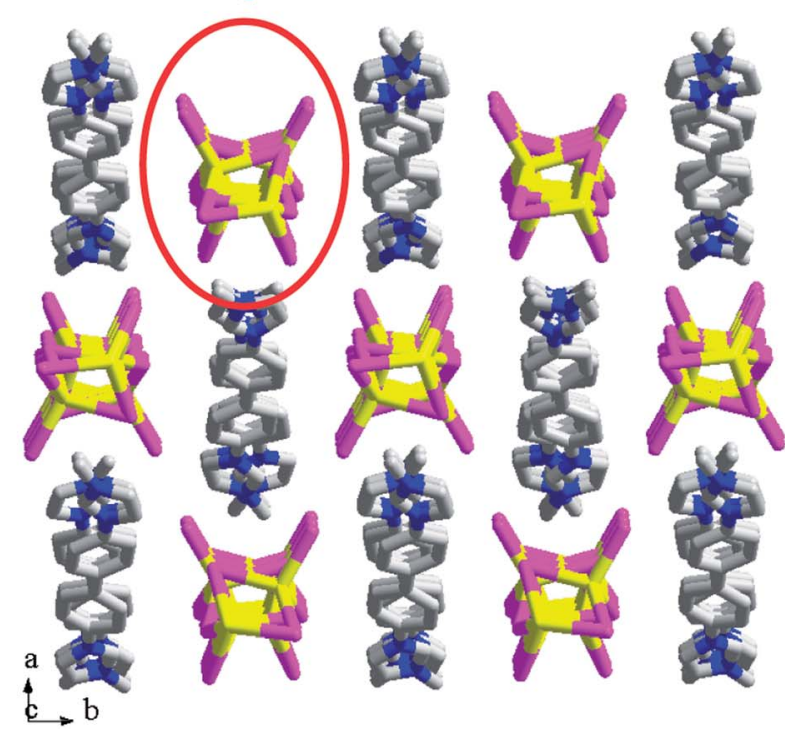

(c)

Fig. 2 Asymmetric unit (a), 1-D chain (b), and projection plot in (001) direction (c) in 2 (a: $x,-y+3 / 2, z+1 / 2 ; b: x,-y+3 / 2, z-1 / 2)$. 
(c)
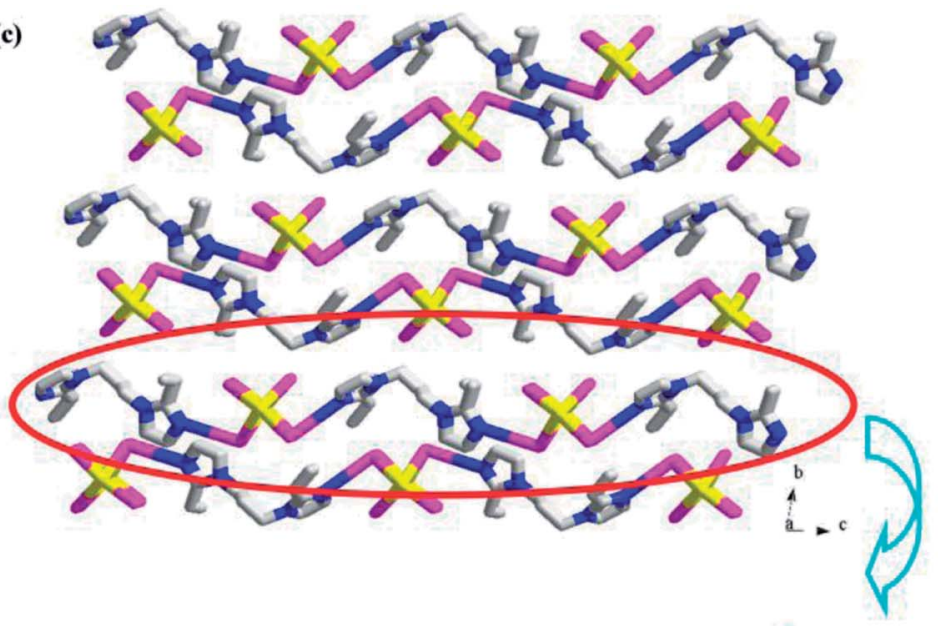

(b)

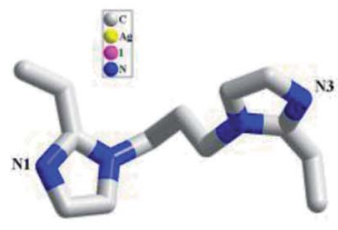

(a)
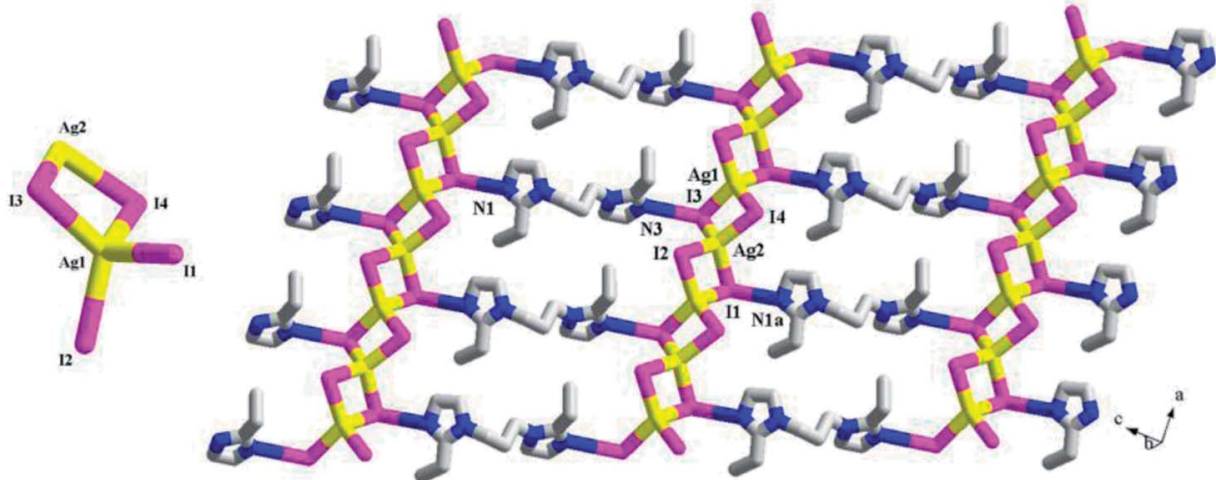
12
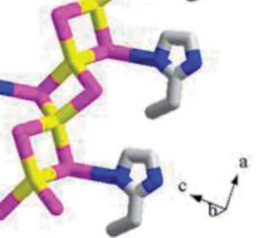

Fig. 3 Asymmetric unit (a), 2-D supramolecular layer (b), and projection plot in (100) direction (c) in 3 (a: $x+1, y, z-1)$.

in the temperature range of $30-800{ }^{\circ} \mathrm{C}$, the weigh loss for all do not end; (ii) 2 and 3 possess the better thermobility, and can be thermal stable up to $\mathrm{ca} .340{ }^{\circ} \mathrm{C}$; (iii) the initial minor weight loss for 1 ( $c a .4 .2 \%$ ) should be attributed to the sublimation of DMF (calcd: $4.5 \%$ ). Ca. 19\% weight loss for the second step for 1 should be assigned to the removal of L1 (calcd: 18.8\%). At this time, the intermediate should be $\mathrm{H}\left[\mathrm{Ag}_{5} \mathrm{I}_{6}\right]$; (iv) the initial weight loss for 2 should correspond to the departure of $[\mathrm{L} 2] \mathrm{I}_{2}$, even though the platform is not obvious; (v) the initial two steps of weight loss for 3 should be assigned to the removal of $\left[\mathrm{H}_{2}(\mathrm{~L} 3)\right] \mathrm{I}_{2}$ (calcd: $51 \%$; found: $50 \%$ ). The solid-state UV-Vis spectra of the title compounds were investigated. As shown in Fig. $\mathrm{S} 4, \uparrow$ the adsorption edges at $416 \mathrm{~nm}$ for 1, $395 \mathrm{~nm}$ for 2 and $354 \mathrm{~nm}$ for 3, suggest that the energy gaps for three hybrids are $2.95 \mathrm{eV}$ for 1, $3.11 \mathrm{eV}$ for 2 and $3.47 \mathrm{eV}$ for 3 , respectively. Compared with the energy gap of AgI $(2.81 \mathrm{eV}),{ }^{18}$ the energy gaps for the title three hybrids all become wide, which should be due to the hybrid. Fig. S5† illustrates the IR spectra of 1-3.

\section{Photoluminescence property}

In order to preliminarily know the photoluminescence properties of the title three compounds, we first recorded their

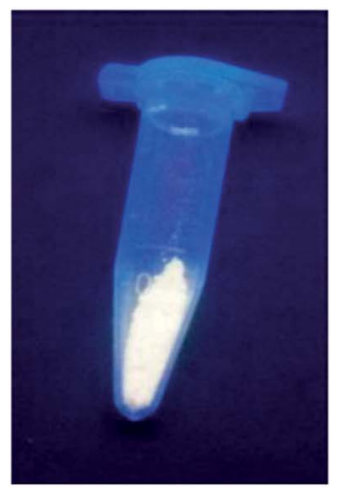

(a)

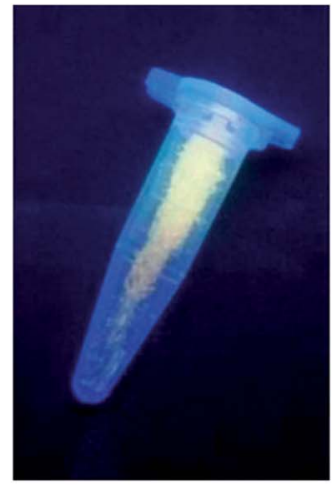

(b)

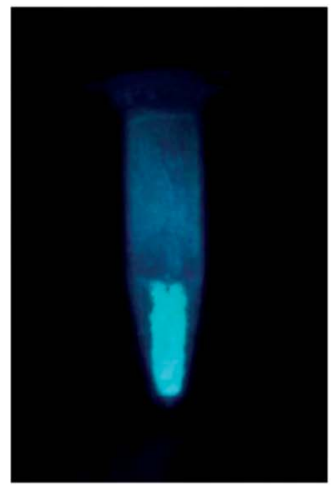

(c)

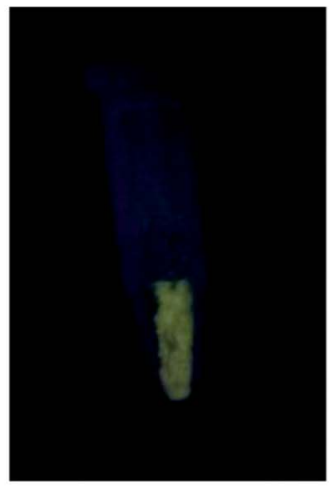

(d)

Fig. 4 Photoluminescence behaviors of 1 (a), 2 (b) and 3 (c and d) under UV lamp at low temperature. 
photoluminescence behaviors under the UV lamp. At the room temperature, the emissions for all are not obvious. However, after the samples were soaked in the liquid nitrogen for a period of time, the different situations appeared. At the low temperature, they all emit light. For 1 and 2, they exhibit the strong yellow-light emissions (Fig. 4a and b). The emissions of 3 are somewhat weak, compared with the emissions of 1 and 2. But interestingly, it shows the different emissions upon excitation at the different wavelengths: a blue-green-light emission when excited at $254 \mathrm{~nm}$ (Fig. 4c); a yellow-light emission when excited at $365 \mathrm{~nm}$ (Fig. 4d). This suggests that 3 might be a potential photochromic luminescence material.

In order to further understand the photoluminescence properties of the title three compounds, we measured their

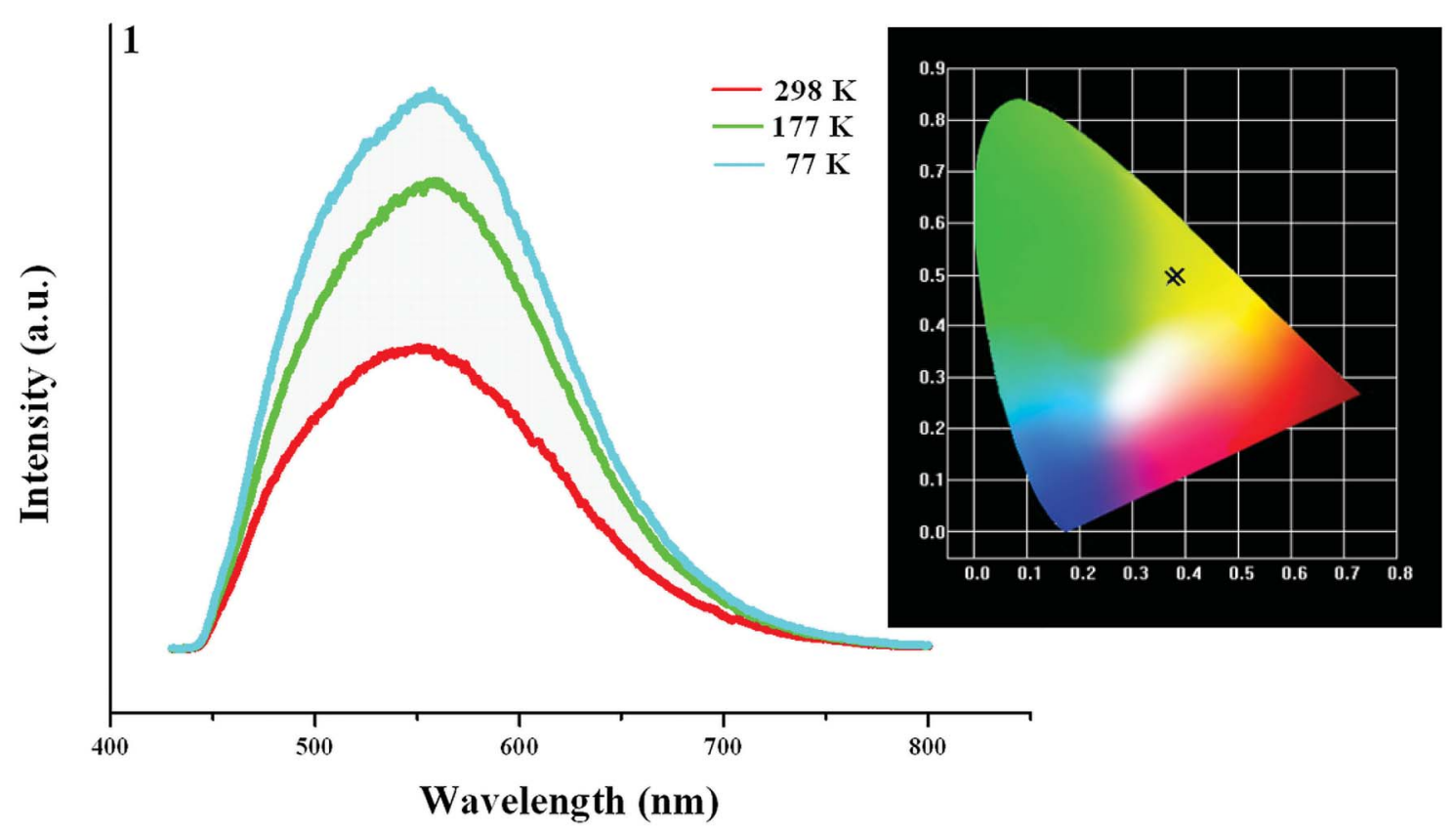

(a)

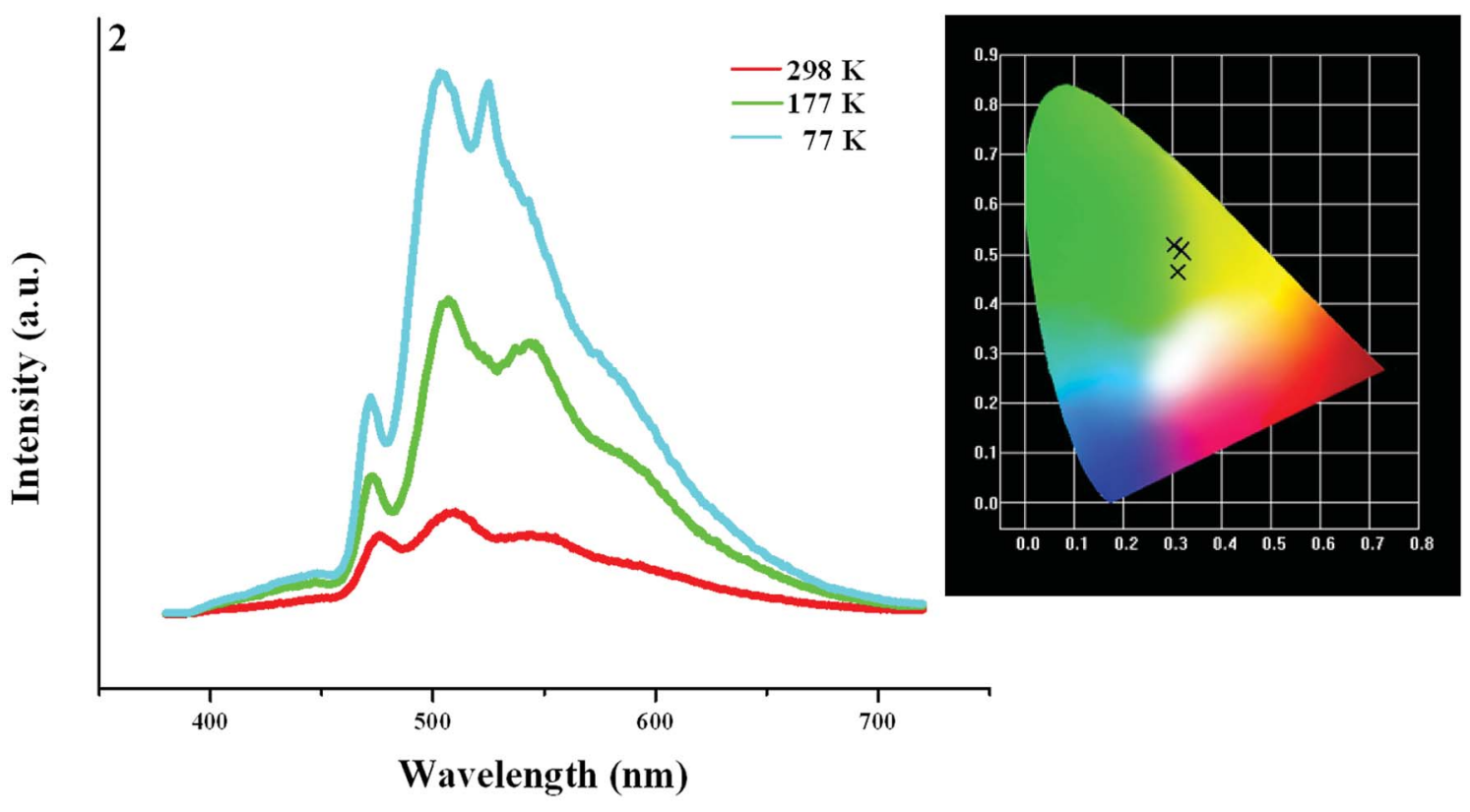

(b)

Fig. 5 Emission spectra of 1 (a) and 2 (b) at 298 K, $177 \mathrm{~K}$ and $77 \mathrm{~K}$ (inserted are corresponding ClE chromaticity diagrams). 
emission spectra at the different temperature. As shown in Fig. 5a, 1 actually emits light at $298 \mathrm{~K}$, but the intensity is not strong. Upon excitation at $398 \mathrm{~nm}, 1$ shows a broad emission, and the maximum appears at $553 \mathrm{~nm}\left(\tau_{1}=13.84 \mu \mathrm{s}, \tau_{2}=598\right.$ $\mu \mathrm{S})$. The corresponding CIE chromaticity coordinates of (0.382, 0.4971) suggests that the broad emission for $\mathbf{1}$ is a yellow-light one. With the decrease of the temperature, the peak positions hardly change, but the emission intensities are obviously strengthened $\left(\tau_{1}=94.67 \mu \mathrm{s}, \tau_{2}=803 \mu \mathrm{s}, \tau_{3}=5.460 \mathrm{~ms}\right.$ at $\left.77 \mathrm{~K}\right)$. Fig. $5 \mathrm{~b}$ displays the emission spectra of 2 at the different temperature. Indeed, 2 also emits light upon excitation $\left(\lambda_{\mathrm{ex}}=\right.$ $358 \mathrm{~nm}$ ) at $298 \mathrm{~K}$, but the emission is extremely weak. Three peaks are found in the emission spectrum of 2, which appear at $475 \mathrm{~nm}, 508 \mathrm{~nm}$, and $553 \mathrm{~nm}$, respectively $\left(\tau_{1}=2.323 \mu \mathrm{s}, \tau_{2}=\right.$ $\left.28.73 \mu \mathrm{s}, \tau_{3}=104.9 \mu \mathrm{s}\right)$. At $177 \mathrm{~K}$, the emission intensity for 2 is obviously improved. The peak positions at $475 \mathrm{~nm}$ and $508 \mathrm{~nm}$ have no change, but the peak at $553 \mathrm{~nm}$ slightly blue-shifts to $543 \mathrm{~nm}$. When the temperature is declined to $77 \mathrm{~K}$, the emission intensity for 2 is further improved. The peak positions at $475 \mathrm{~nm}$ and $508 \mathrm{~nm}$ still have no change, but the peak at $553 \mathrm{~nm}$

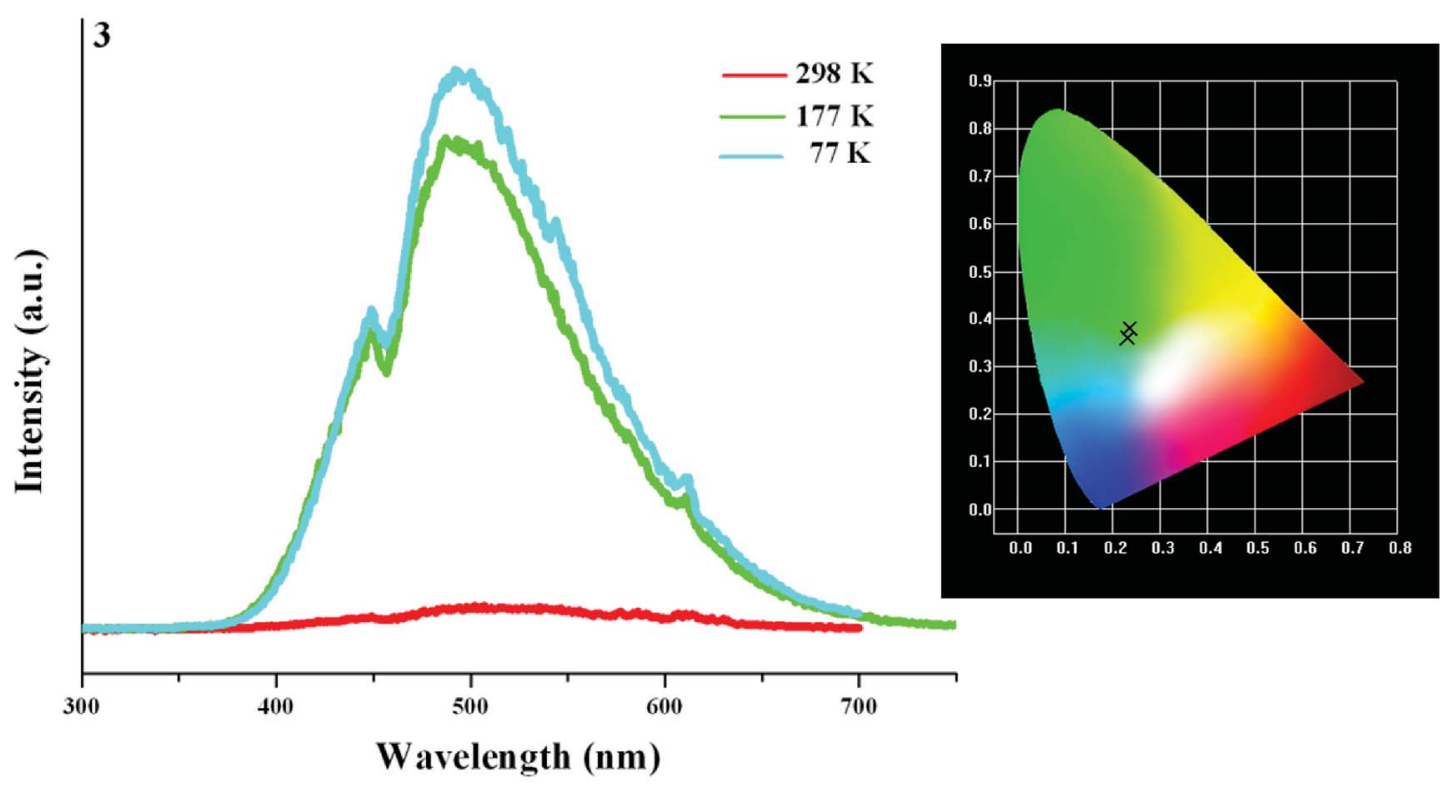

(a)

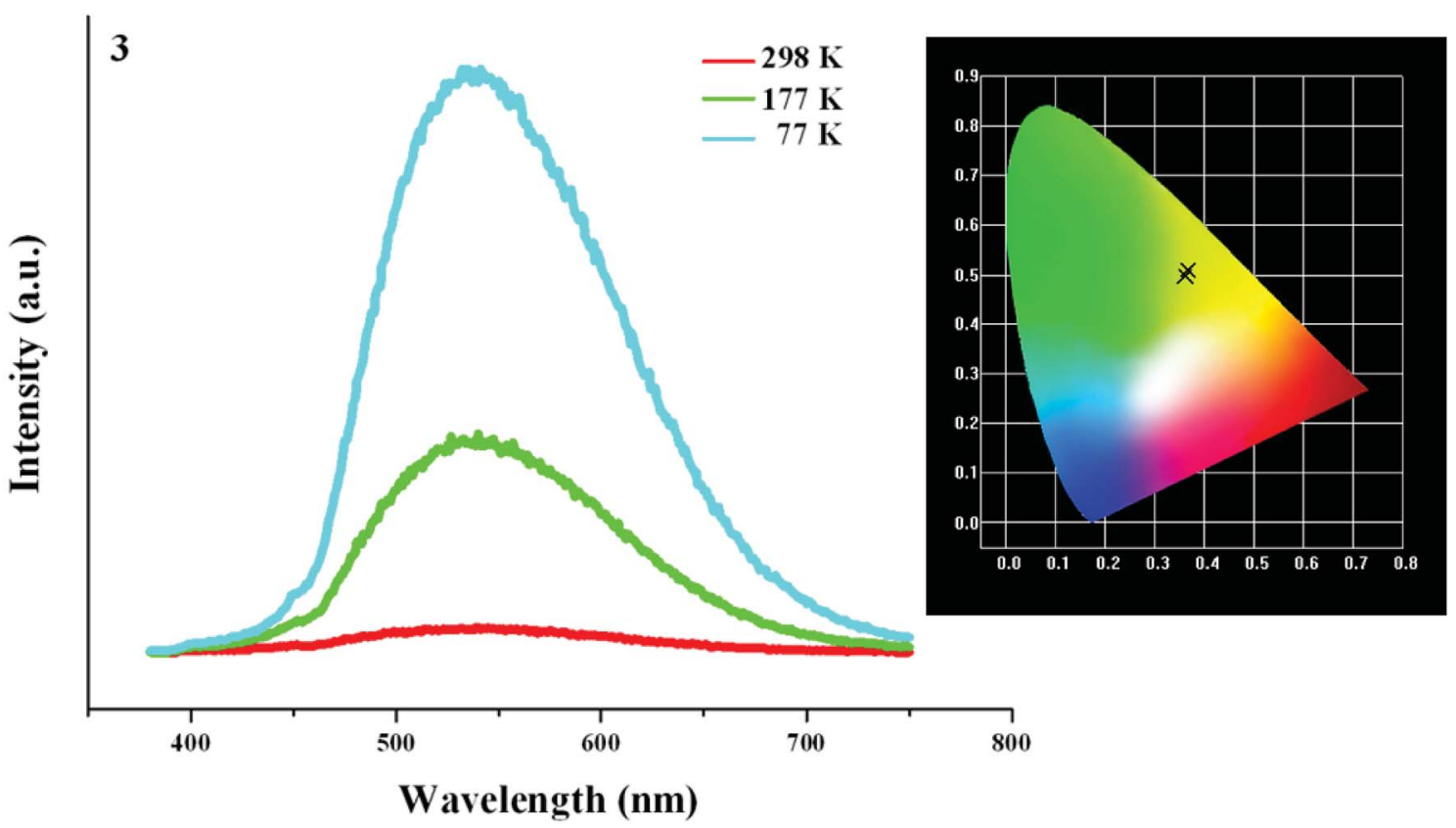

(b)

Fig. 6 Emission spectra of 3 at 298 K, $177 \mathrm{~K}$ and $77 \mathrm{~K}$ when excited at $254 \mathrm{~nm}$ (a) and $365 \mathrm{~nm}$ (b). 
further blue-shifts to $523 \mathrm{~nm}\left(\tau_{1}=436.9 \mu \mathrm{s}, \tau_{2}=1.663 \mathrm{~ms}, \tau_{3}=\right.$ $6.931 \mathrm{~ms}$ at $77 \mathrm{~K})$. Although a large blue shift $(30 \mathrm{~nm})$ for the peak at $553 \mathrm{~nm}$ occurs, this does not alter the emission of 2 . From 298 K to 77 K, 2 always emits the yellow light, based on the corresponding CIE chromaticity coordinates $((0.3091,0.4642)$ at $298 \mathrm{~K} ;(0.321,0.507)$ at $177 \mathrm{~K} ;(0.3021,0.5199)$ at $77 \mathrm{~K})$.

Based on the photoluminescence behavior of 3 under the UV lamp, we first measured the emission spectra of $\mathbf{3}$ at the different temperature when excited at $254 \mathrm{~nm}$. As shown in Fig. 6(a), at $298 \mathrm{~K}, 3$ really does not emit light upon excitation at $254 \mathrm{~nm}$. At $177 \mathrm{~K}, 3$ exhibits a strong emission with the maximum at $494 \mathrm{~nm}$. The corresponding CIE chromaticity coordinates of $(0.2288,0.359)$ suggests a blue-green-light emission. At $77 \mathrm{~K}$, the emission intensity of 3 is slightly strengthened, but the peak position does not change. Then we measured the emission spectra of 3 at the different temperature when excited at $365 \mathrm{~nm}$. At $298 \mathrm{~K}, 3$ still does not emit light. At $177 \mathrm{~K}, 3$ exhibits a weak emission with the maximum at $540 \mathrm{~nm}$, which is defined as a yellow-light emission based on the corresponding the CIE chromaticity coordinates of (0.3622, 0.4966). At $77 \mathrm{~K}, 3$ still emit the yellow light (CIE chromaticity coordinates: $(0.3684,0.508)$ ), but the intensity is largely improved (see Fig. 6b). The statements above mean that at the low temperature, 3 emits the different light upon excited at the different wavelengths: a blue-green-light upon excitation at 254; a yellow-light upon excitation at $365 \mathrm{~nm}$. That is to say, 3 possesses the luminescence photochromic property, and it is a potential photochromic luminescence material. The results from the emission spectra of $\mathbf{3}$ are completely in agreement with the photoluminescence behaviors of 3 under the UV lamp. In order to deeply understand the luminescence photochromic property, we measured the emission spectra of 3 at $77 \mathrm{~K}$ when excited at the different wavelengths from $254 \mathrm{~nm}$ to $365 \mathrm{~nm}$. As shown in Fig. 7, with the change of excitation wavelength from
$254 \mathrm{~nm}$ to $365 \mathrm{~nm}$, the corresponding CIE chromaticity coordinates of the emission spectra gradually transfer from the blue green to the final yellow.

With the decrease of the temperature, even though the emission intensities for all are improved, they still emit the same light. This suggests that the title three compounds are not the luminescence thermochromic materials. We speculate that a slight distortion for the Ag-I clusters in 1-3 should occur at the low temperature. However, maybe the photoluminescence behavior for the Ag-I cluster is not sensitive, so this minor change in molecular structure does not lead to a large variation of the photoluminescence property. The yellow-light emissions at $553 \mathrm{~nm}$ for 1 and $508 \mathrm{~nm}$ for 2 should be attributed to a mixture of the I-to-Ag charge transfer and the $\mathrm{Ag}^{\mathrm{I}} \mathrm{d}^{10}-\mathrm{d}^{9} \mathrm{~s}^{1}$ transition based on the short Ag $\cdots \mathrm{Ag}$ interactions, because some reported hybrid iodoargentates exhibit a similar emission, and they have been assigned to this attribution. ${ }^{2,6} \mathrm{With}$ the decrease of the temperature, the photoluminescence lifetimes for $\mathbf{1}$ and $\mathbf{2}$ are longer. This should be related to the change of molecular thermal vibration. At $298 \mathrm{~K}$, the molecular thermal vibration is active, and partial energy is consumed in the form of nonradiative transition. While at $77 \mathrm{~K}$, the molecular thermal vibration is not active, and more energy participates in the radiative transition. Interestingly, with the change of excitation wavelength, the emission of $\mathbf{3}$ exhibits a color change from the blue green to the yellow. This suggests that $\mathbf{3}$ is a potential luminescence photochromic material. 3 is just a simple hybrid, in which there only exist two potential charge transferring paths: the ligand-centered electronic excitations; a mixture of the I-to-Ag charge transfer and the $\mathrm{Ag}^{\mathrm{I}} \mathrm{d}^{10}-\mathrm{d}^{9} \mathrm{~s}^{1}$ transition. Therefore, the emission centered at $494 \mathrm{~nm}$ in 3 should be originated from the former (L3 exhibits a similar emission with the maximum at $460 \mathrm{~nm}$ (Fig. S6†)), whereas the emission centered at $540 \mathrm{~nm}$ should be derived from the latter. The

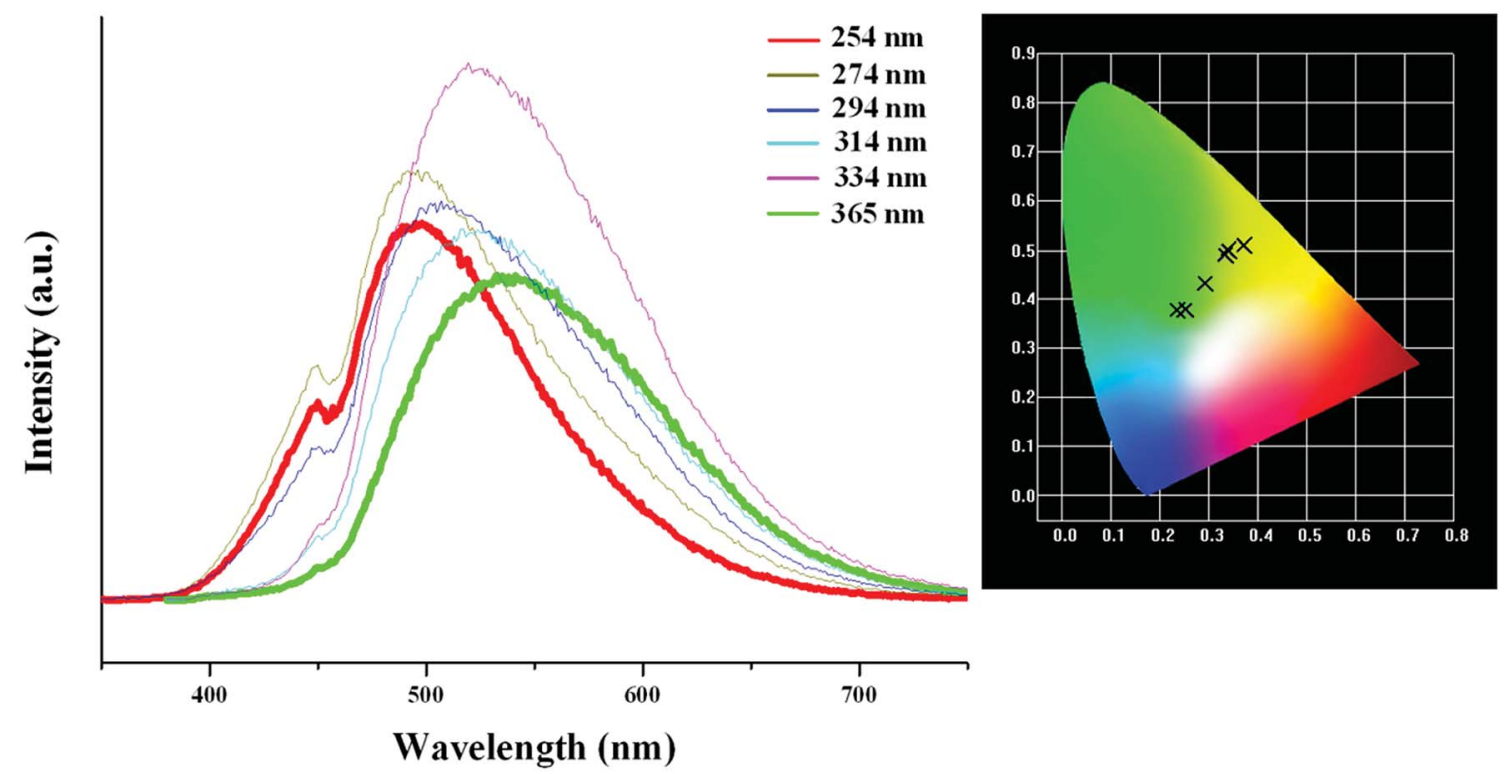

Fig. $7 \mathrm{ClE}$ chromaticity coordinates of 3 , showing color change from blue-green to yellow upon varying excitation wavelength from $254 \mathrm{~nm}$ to $365 \mathrm{~nm}$. 
existence of these two emissions should be responsible for the photoluminescence photochromic property of $\mathbf{3}$. For $\mathbf{1}$ and $\mathbf{2}$, the ligand-centered electronic excitations do not occur. This is to say, the electron in the excited-state energy level does not decays nonradiatively to the $\pi^{*}$ orbitals of the organic molecule, ${ }^{19}$ so 1 and 2 do not exhibit the photoluminescence photochromic behaviors. Fig. S7 $\uparrow$ gives the decay curves of 1 and 2 at $298 \mathrm{~K}$ and $77 \mathrm{~K}$.

\section{Conclusion}

In summary, we reported the synthesis, structural characterization, and the photoluminescence properties of three new bisimidazole-based iodoargentates. Synthetically, $\mathrm{pH}$ plays a key role in the reactions. It not only affects the protonation of bisimidazole molecules, but also affects the N-alylation of bisimidazole molecules with alcohol solvents. Structurally, three different chained iodoargentates are observed in 1-3: a tube-like chain in 1; a cluster-based chain in 2; a simple single chain in 3. The bisimidazole molecule as the countercation plays a key role. By the size, charge, flexibility/rigidity and the hydrogen-bonded interactions, it controls the formation of the inorganic iodoargentates. Meanwhile, it also determines the structure of the overall supramolecular network for the assynthesized hybrid. Only in the limited examples, the iodoargentates in $\mathbf{1}$ and $\mathbf{2}$ are found. Even though the iodoargentate in $\mathbf{3}$ is simple, the photoluminescence analysis reveals that at the low temperature, it possesses the photoluminescence photochromic property: a blue-green-light emission upon excitation at $254 \mathrm{~nm}$; a yellow-light emission upon excitation at $365 \mathrm{~nm}$. The photoluminescence analysis also indicates that at $77 \mathrm{~K}, 1$ and 2 emit the strong yellow light with the ms-grade photoluminescence lifetimes.

\section{Conflicts of interest}

There are no conflicts to declare.

\section{Acknowledgements}

The authors are grateful to the financial aid from the National Natural Science Foundation of China (Grant No. 21771076, 21271083).

\section{References}

1 (a) T. L. Yu, G. X. Wu, Z. G. Wang and Y. L. Fu, J. Cluster Sci., 2018, 29, 443-449; (b) L. S. Song, H. M. Wang, Y. Y. Niu, H. W. Hou and Y. Zhu, CrystEngComm, 2012, 14, 49274938; (c) Q. Q. Wu, P. Huang, L. T. Fan, M. Li, Z. R. Chen, Y. Li and H. H. Li, Chin. J. Struct. Chem., 2016, 35, 16371644; (d) H. B. Duan, S. S. Yu and Z. Hong, Mater. Res. Bull., 2015, 65, 137-141; (e) G. Saha, K. K. Sarker, C. J. Chen, J. Cheng, T. H. Lu, G. Mostafa and C. Sinha, Polyhedron, 2009, 28, 3586-3592; (f) X. Chen, Z. Y. Yao, C. Xue, Z. X. Yang, J. L. Liu and X. M. Ren, CrystEngComm, 2018, 20, 356-361; $(g)$ S. S. Yu, S. X. Liu, Y. X. Zhu,
H. B. Duan and H. Zhang, RSC Adv., 2017, 7, 56153-56156; (h) S. Mishra, E. Jeanneau, S. Daniele and G. Ledoux, Dalton Trans., 2008, 6296-6304; (i) J. M. Yue, Y. Y. Niu, B. Zhang, S. W. Ng and H. W. Hou, CrystEngComm, 2011, 13, 2571-2577; (j) G. N. Liu, L. L. Liu, Y. N. Chu, Y. Q. Sun, Z. W. Zhang and C. C. Li, Eur. J. Inorg. Chem., 2015, 478487; (k) S. Mishra, E. Jeanneau, G. Ledoux and S. Daniele, Inorg. Chem., 2014, 53, 11721-11731.

2 (a) Q. Y. Chen, X. Cheng, T. Wang, Z. H. Yu, C. Zhang, S. K. Liu, H. H. Li and Z. R. Chen, Z. Anorg. Allg. Chem., 2014, 640, 439-443; (b) Y. L. Shen, J. L. Lu, C. Y. Tang, W. Fang, Y. Zhang and D. X. Jia, RSC Adv., 2014, 4, 3959639605; (c) T. L. Yu, J. J. Shen, Y. B. Fu and Y. L. Fu, CrystEngComm, 2014, 16, 5280-5289; (d) T. L. Yu, H. H. Li, P. F. Hao, J. J. Shen and Y. L. Fu, Eur. J. Inorg. Chem., 2016, 4878-4884; (e) Y. Z. Qiao, W. Z. Fu, J. M. Yue, X. C. Liu and H. W. Hou, CrystEngComm, 2012, 14, 3241-3249.

3 D. H. Wang, L. M. Zhao, X. Y. Lin, Y. K. Wang, W. T. Zhang, K. Y. Song, H. H. Li and Z. R. Chen, Inorg. Chem. Front., 2018, 5, 1162-1173.

4 (a) M. Liu, Y. Liang, C. H. Wang, C. J. Ma and Y. Y. Niu, J. Cluster Sci., 2015, 26, 1723-1733; (b) C. Y. Yue, B. Hu, X. W. Lei, R. Q. Li, F. Q. Mi, H. Gao, Y. Li, F. Wu, C. L. Wang and N. Lin, Inorg. Chem., 2017, 56, 1096210970; (c) X. W. Lei, C. Y. Yue, L. J. Feng, Y. F. Han, R. R. Meng, J. T. Yang, H. Ding, C. S. Gao and C. Y. Wang, CrystEngComm, 2016, 18, 427-436; (d) X. W. Lei, C. Y. Yue, S. Wang, H. Gao, W. Wang, N. Wang and Y. D. Yin, Dalton Trans., 2017, 46, 4209-4217.

5 (a) G. C. Xiao, J. Cluster Sci., 2006, 17, 457-466; (b) Y. Y. Niu, Y. L. Song, H. W. Hou and Y. Zhu, Inorg. Chem., 2005, 44, 2553-2559; (c) H. H. Li, Z. R. Chen, J. Q. Li, C. C. Huang, Y. F. Zhang and G. X. Jia, Eur. J. Inorg. Chem., 2006, 24472453.

6 (a) H. H. Li, Z. R. Chen, J. Q. Li, J. Q. Li, C. C. Huang, X. L. Hu, B. Zhao and Z. X. Ni, J. Cluster Sci., 2005, 16, 537-545; (b) H. H. Li, S. Y. Chen, H. J. Dong, Y. L. Wu and Z. R. Chen, J. Chem. Crystallogr., 2011, 41, 858-863; (c) H. H. Li, Z. R. Chen, J. Q. Li, C. C. Huang, Y. F. Zhang and G. X. Jia, Eur. J. Inorg. Chem., 2006, 2447-2453; (d) H. H. Li, Z. R. Chen, J. Q. Li, C. C. Huang, Y. F. Zhang and G. X. Jia, Cryst. Growth Des., 2006, 6, 1813-1820; (e) H. H. Li, Y. Y. Xing, Z. X. Lian, A. W. Gong, H. Y. Wu, Y. Li and Z. R. Chen, CrystEngComm, 2013, 15, 1721-1728; (f) H. H. Li, J. X. Wu, H. J. Dong, Y. L. Wu and Z. R. Chen, J. Mol. Struct., 2011, 987, 180-185; (g) H. H. Li, Z. R. Chen, L. C. Cheng, G. M. Feng, H. D. Zheng and J. Q. Li, Dalton Trans., 2009, 4888-4895.

7 (a) Y. R. Qiao, P. F. Hao and Y. L. Fu, Inorg. Chem., 2015, 54, 8705-8710; (b) J. J. Shen, F. Wang, X. X. Li, T. T. Yu, P. F. Hao and Y. L. Fu, RSC Adv., 2016, 6, 98916-98920; (c) Y. C. Zhu, T. L. Yu, P. F. Hao, J. J. Shen and Y. L. Fu, J. Cluster Sci., 2016, 27, 1283-1291; (d) P. F. Hao, Y. R. Qiao, T. L. Yu, J. J. Shen, D. T. Dai and Y. L. Fu, RSC Adv., 2016, 6, 8762887636; (e) T. L. Yu, P. F. Hao, J. J. Shen, H. H. Li and Y. L. Fu, Dalton Trans., 2016, 45, 16505-16510; $(f)$ T. L. Yu, J. J. Shen, Y. L. Wang and Y. L. Fu, Eur. J. Inorg. Chem., 
2015, 1989-1996; (g) P. F. Hao, L. F. Zhang, J. J. Shen and Y. L. Fu, Dyes Pigm., 2018, 153, 284-290; $(h)$ C. F. Zhang, J. J. Shen, Q. Guan, T. L. Yu and Y. L. Fu, Solid State Sci., 2015, 46, 14-18; (i) J. J. Shen, C. F. Zhang, T. L. Yu, L. An and Y. L. Fu, Cryst. Growth Des., 2014, 14, 6337-6342; (j) T. L. Yu, L. An, L. Zhang, J. J. Shen, Y. B. Fu and Y. L. Fu, Cryst. Growth Des., 2014, 14, 3875-3879.

8 (a) X. W. Lei, C. Y. Yue, F. Wu, X. Y. Jiang and L. N. Chen, Inorg. Chem. Commun., 2017, 77, 64-67; (b) X. W. Lei, C. Y. Yue, J. Q. Zhao, Y. F. Han, J. T. Yang, R. R. Meng, C. S. Gao, H. Ding, C. Y. Wang and W. D. Chen, Cryst. Growth Des., 2015, 15, 5416-5426; (c) X. W. Lei, C. Y. Yue, J. Q. Zhao, Y. F. Han, J. T. Yang, R. R. Meng, C. S. Gao, H. Ding, C. Y. Wang, W. D. Chen and M. C. Hong, Inorg. Chem., 2015, 54, 10593-10603; (d) C. Y. Yue, X. W. Lei, Y. F. Han, X. X. Lu, Y. W. Tian, J. Xu, X. F. Liu and X. Xu, Inorg. Chem., 2016, 55, 12193-12203; (e) X. W. Lei, C. Y. Yue, J. C. Wei, R. Q. Li, Y. Lia and F. Q. Mi, Dalton Trans., 2016, 45, 19389-19398; (f) C. Y. Yue, X. W. Lei, X. X. Lu, Y. Li, J. C. Wei, W. Wang, Y. D. Yin and N. Wang, Dalton Trans., 2017, 46, 9235-9244; (g) X. W. Lei, C. Y. Yue, J. Q. Zhao, Y. F. Han, Z. R. Ba, C. Wang, X. Y. Liu, Y. P. Gong and X. Y. Liu, Eur. J. Inorg. Chem., 2015, 44124419; (h) X. W. Lei, C. Y. Yue, J. C. Wei, R. Q. Li, F. Q. Mi, Y. Li, L. Gao and Q. X. Liu, Chem.-Eur. J., 2017, 23, 1454714553.

9 (a) G. N. Liu, X. M. Jiang, Q. S. Fan, M. B. Hussain, K. Li, H. Sun, X. Y. Li, W. Q. Liu and C. Li, Inorg. Chem., 2017, 56, 1906-1918; (b) J. J. Hou, S. L. Li, C. R. Li and X. M. Zhang, Dalton Trans., 2010, 39, 2701-2707; (c) H. Chan, Y. Chen, M. Dai, C. N. Lü, H. F. Wang, Z. G. Ren, Z. J. Huang, C. Y. Ni and J. P. Lang, CrystEngComm, 2012, 14, 466-473; (d) Y. Chen, Z. Yang, C. X. Guo, C. Y. Ni, Z. G. Ren, H. X. Li and J. P. Lang, Eur. J. Inorg. Chem., 2010, 5326-5333; (e) G. M. Wang, J. Q. Jiao, X. Zhang, X. M. Zhao, X. Yin, Z. H. Wang, Y. X. Wang and J. H. Lin, Inorg. Chem. Commun., 2014, 39, 94-98; (f) G. M. Wang, J. H. Lin, J. Q. Jiao, X. Zhang, X. M. Zhao, X. Yin, J. S. Huang, Y. X. Wang and J. H. Lin, Inorg. Chem. Commun., 2014, 43, 105-109.

10 R. Y. Wang, X. Zhang, Q. S. Huo, J. H. Yu and J. Q. Xu, RSC Adv., 2017, 7, 19073.

11 (a) Z. Deng, L. Tong, M. Flores, S. Lin, J. X. Cheng, H. Yan and Y. Liu, J. Am. Chem. Soc., 2011, 133, 5389-5396; (b) K. Neinhaus, H. Nar, R. Heiker, J. Wiedenmann and G. U. Nienhaus, J. Am. Chem. Soc., 2008, 130, 12578-12579; (c) Y. Cui, Y. Yue, G. Qian and B. Chen, Chem. Rev., 2012, 12, 1126-1162.
12 (a) Z. X. Fu, J. Lin, L. Wang, C. Li, W. B. Yan and T. Wu, Cryst. Growth Des., 2016, 16, 2322-2327; (b) T. Hayashi, A. Kobayashi, H. Ohara, M. Yoshida, T. Matsumoto, H. Chang and M. Kato, Inorg. Chem., 2015, 54, 8905-8913; (c) K. Kirakci, K. Fejfarová, J. Martinčí, M. Nikl and K. Lang, Inorg. Chem., 2017, 56, 4609-4614; (d) S. S. Zhao, L. Wang, Y. J. Liu, L. Chen and Z. G. Xie, Inorg. Chem., 2017, 56, 13975-13981; (e) S. Z. Zhan, M. Li, J. Zheng, Q. J. Wang, S. W. Ng and D. Li, Inorg. Chem., 2017, 56, 13446-13455; (f) S. Q. Bai, D. Kai, K. L. Ke, M. Lin, L. Jiang, Y. Jiang, D. J. Young, X. J. Loh, X. Li and T. S. A. Hor, ChemPlusChem, 2015, 80, 1235-1240; (g) D. Sun, S. Yuan, H. Wang, H. F. Lu, S. Y. Feng and D. F. Sun, Chem. Commun., 2013, 49, 6152-6154; (h) S. Yuan, H. Wang, D. X. Wang, H. F. Lu, S. Y. Feng and D. Sun, CrystEngComm, 2013, 15, 7792-7802; (i) X. C. Shan, F. L. Jiang, D. Q. Yuan, H. B. Zhang, M. Y. Wu, L. Chen, J. Wei, S. Q. Zhang, J. Pan and M. C. Hong, Chem. Sci., 2013, 4, 1484-1489; (j) J. H. Wang, M. Li, J. Zheng, X. C. Huang and D. Li, Chem. Commun., 2014, 50, 91159118; (k) L. Maini, D. Braga, P. P. Mazzeo, L. Maschio, M. Rérat, I. Manete and B. Ventura, Dalton Trans., 2015, 44, 13003-13006; (l) G. Zeng, S. H. Xing, X. Han, B. J. Xin, X. R. Wang, G. H. Li, Z. Shi and S. H. Feng, RSC Adv., 2015, 5, 40792-40797; $(m)$ F. Farinella, L. Maini, P. P. Mazzeo, V. Fattori, F. Monti and D. Braga, Dalton Trans., 2016, 45, 17939-17947; (n) M. S. Deshmukh, A. Yadav, R. Pant and R. Boomishankar, Inorg. Chem., 2015, 54, 1337-1345; (o) D. M. Zink, T. Baumann, J. Friedrichs, M. Nieger and S. Bräse, Inorg. Chem., 2013, 52, 13509-13520.

13 S. L. Li, J. Wang, F. Q. Zhang and X. M. Zhang, Cryst. Growth Des., 2017, 17, 746-752.

14 Z. P. Wang, J. Y. Wang, J. R. Li, M. L. Feng, G. D. Zou and X. Y. Huang, Chem. Commun., 2015, 51, 3094-3097.

15 L. Z. Cai, M. S. Wang, M. J. Zhang, G. E. Wang, G. C. Guo and J. S. Huang, CrystEngComm, 2012, 14, 6196-6200.

16 G. M. Sheldrick, Acta Crystallogr., Sect. A: Found. Crystallogr., 2008, 64, 112-122.

17 (a) L. Chen, J. Ma, Q. H. Chen, R. Feng, F. L. Jiang and M. C. Hong, Inorg. Chem. Commun., 2012, 15, 208-211; (b) H. Park, E. Kwon, H. Chiang, H. Im, K. Y. Lee, J. Kim and T. H. Kim, Inorg. Chem., 2017, 56, 8287-8294.

18 T. Yu, Y. Fu, Y. Wang, P. Hao, J. Shen and Y. Fu, CrystEngComm, 2015, 17, 8752-8761.

19 J. Lu, K. Zhao, Q. R. Fang, J. Q. Xu, J. H. Yu, X. Zhang, H. Y. Bie and T. G. Wang, Cryst. Growth Des., 2005, 5, 1091-1098. 